\title{
DAS DIFICULDADES ÉTICAS E PESSOAIS NO COMBATE AOS CRIMES DE VIOLÊNCIA DOMÉSTICA NO ÂMBITO DA COMARCA DE PORTO ALEGRE DO NORTE/MT
}

\author{
OF THE ETHICAL AND PERSONAL DIFFICULTIES IN COMBATING CRIMES OF \\ DOMESTIC VIOLENCE WITHIN THE REGION OF PORTO ALEGRE DO NORTE/MT
}

\author{
Maykon de Lima Bessa ${ }^{1}$ \\ Andressa Bessa Machado Lima
}

Recebido: $15 / 10 / 2020$

Aceito: 28/12/2020

Resumo: A fim de demonstrar à sociedade e, principalmente, às mulheres a importância de se tomar medidas para combater os crimes de violência doméstica, fez-se um estudo e levantamento de dados extraídos junto aos sistemas do Poder Judiciário dos números reais de violência doméstica no âmbito da Comarca de Porto Alegre do Norte, além de trazer conceitos científicos, doutrinários, jurisprudenciais e legais sobre o tema. Abordou-se também, as implicações éticas e familiares, bem como a ausência assistência do Estado no combate ou inibição do crescimento dos crimes de violência doméstica. A pesquisa foi realizada utilizando-se método teórico juntamente com o empírico e, ao final, demonstrou-se quais mecanismos serão eficientes no combate à violência doméstica, ante o constante crescimento dessa modalidade de delito, conforme se depreende dos dados apresentados no decorrer deste trabalho.

Palavras-chave: Violência Doméstica; Agressão familiar; Comarca de Porto Alegre do Norte/MT.

Abstract: In order to demonstrate to society and to women (especially), mainly, the importance of taking measures to fight the crimes of domestic violence, a study and survey of data extracted from the systems of the Judiciary of the real numbers of domestic violence in the District of Porto Alegre do Norte, besides bringing scientific, doctrinal, jurisprudential and legal concepts on the subject. The ethical and family implications also discussed were, as well as the lack of assistance from the State in combating or inhibiting the growth of domestic violence crimes. The research was carried out using theoretical methods together with empirical methods and, at the end, it was demonstrated which mechanisms will be efficient in the fight against domestic violence, given the constant growth of this type of crime, as can be seen from the data presented during this work.

Key words: Domestic Violence; Family aggression; County of Porto Alegre do Norte/MT.

1 Graduado em Direito pela Universidade de Rio Verde (UniRV), campus Caiapônia, Estado de Goiás e pósgraduando em Direitos Humanos e Garantias Fundamentais pela Universidade do Estado de Mato Grosso (UNEMAT). E-mail: maykonlima.bessa@gmail.com

2 Graduanda em Filosofia pela Universidade do Estado de Mato Grosso (UNEMAT) e pós-graduanda em Direitos Humanos e Garantias Fundamentais pela mesma instituição. E-mail: andreessabessa@gmail.com 


\title{
1 Introdução
}

Sabe-se que a violência, em modo geral, sempre esteve presente no seio da sociedade. A violência em desfavor das mulheres não é diferente. No Brasil, segundo o site UOL (2019), citando o Jornal Folha de S. Paulo, informa que "a cada 04 minutos uma mulher é agredida no Brasil”3. Em um dia (24h), seguindo esse número, 360 mulheres são violentas no âmbito doméstico.

Neste Estado de Mato Grosso, no ano de 2019, o Poder Judiciário recebeu 6.455 pedidos de medidas protetivas, sendo que 6.351 foram concedidas ${ }^{4}$. Considerando apenas as medidas concedidas, neste Estado são registradas 17,4 medidas protetivas por dia. Em âmbito nacional, este Estado é responsável, por aproximadamente, 4,83\% dos casos.

Na Comarca de Porto Alegre do Norte, a qual abrange os seguintes municípios: Canabrava do Norte, Confresa, Porto Alegre do Norte e São José do Xingu, foram distribuídas 130 medidas protetivas no ano de 2019 - segundo os sistemas Apolo e PJ e do Poder Judiciário ${ }^{5}$. Equivalentemente, a cada 3 (três) dias, 1 (uma) mulher registrava medidas protetivas, em razão de algum tipo de agressão.

Não bastasse, durante o período de quarentena, imposto pelo novo coronavírus (Covid-19), em muito se agravou, inclusive os casos de violência doméstica, bem em conta do tempo em que as pessoas ficaram no interior dos lares, elevando o contato diário e, consequentemente, a prática dessa modalidade delitiva. O site do Senado Federal expõe que:

\begin{abstract}
foram identificadas cerca de 52 mil menções contendo indicativo de briga entre casais vizinhos. Mais de $10 \%$ delas (5.583) indicavam violência doméstica. No entanto, o número de denúncias diminuiu em $8,6 \%$ somando os estados analisados: de 8.440 casos em março de 2019 para 7.714 no mesmo período de 2020. Já o Ministério mostra um aumento de 17,89\% de denúncias no disque denúncia (180) em março de 2020 comparado a março de $2019^{6}$.
\end{abstract}

Percebe-se que os números são preocupantes, demonstrando ser um problema que extrapola os limites da justiça, abrangendo, certamente, os problemas pessoal, social, político e, principalmente, um problema cultural em nosso país.

3 Disponível em: <https://www.uol.com.br/universa/noticias/redacao/2019/09/09/levantamento-a-cada-4minutos-uma-mulher-e-agredida-no-brasil.htm $>$.

${ }^{4}$ Disponível em: <https://www.tjmt.jus.br/noticias/58623\#.XpMm08hKjIU>.

${ }^{5} \mathrm{O}$ acesso ao referido sistema foi autorizado pelo Juízo da $3^{\mathrm{a}}$ Vara da Comarca de Porto Alegre do Norte/MT, por meio do Ofício n. 52/2019-CPAN

${ }^{6}$ Disponível em: < https://www12.senado.leg.br/noticias/materias/2020/09/03/tv-senado-live-discute-o-aumentoda-violencia-domestica-durante-a-pandemia . 
Quanto aos limites da justiça, os problemas se dão em razão da escassez de servidores públicos e quantidade insuficiente de varas especializadas para processar e julgar os casos de violência doméstica, que, na maioria das Comarcas espalhadas no território brasileiro, os casos são processados e julgados por juízos de vara única, ou uma vara criminal que é competente para diversos ou todos os crimes daquela jurisdição.

Em relação aos problemas pessoais, os motivos são derivados, por exemplo: i) que a denúncia só faz aumentar os casos de violência nos lares; II) que não denuncia para preservar o relacionamento; III) que não há punição ao agressor; IV) que depende, social e economicamente, do agressor; V) que não há lugares para apresentar a denúncia e VI) que são aconselhadas, ou pela família ou pela autoridade policial, a não denunciar. Quem traz os dados é o site do JusBrasil (2011). Nestes termos:

$\mathrm{Na}$ opinião de $28 \%$ dos que disseram que as mulheres não estavam denunciando mais, a principal razão era por que a denúncia só fazia aumentar a violência em casa (28\% das mulheres, $28 \%$ dos homens). Vinte e cinco por cento disse que as mulheres não denunciavam para preservar casamento e família (24\% das mulheres, $26 \%$ dos homens); $19 \%$, porque não acontecia nada com o agressor (18\% das mulheres, $20 \%$ dos homens); $15 \%$, porque a mulher dependia economicamente do companheiro (18\% das mulheres, $12 \%$ dos homens); $3 \%$, porque as mulheres não tinham onde denunciar (3\% das mulheres, $4 \%$ dos homens); $1 \%$, porque a família/delegado aconselha a não denunciar (1\% das mulheres, $0 \%$ dos homens). ${ }^{7}$

No que tange aos limites político, compreende-se que, apesar da evolução histórica no combate aos crimes de violência doméstica, ainda tem muito que se melhorar. Em todas as esferas da Federação: União, Estados, Distrito Federal e Municípios, o Poder Executivo, junto ao Legislativo, pouco garante, pouco previne e pouco remedia os casos de violência doméstica. Como se sabe - e que demonstraremos no decorrer deste trabalho -, as delegacias especializadas são insuficientes, não há servidores públicos capacitados em um número adequado e, em modo geral, as leis ou os sistemas existentes não são capazes de subsidiar aplicações de penas apropriados para prevenir, punir e, ao mesmo tempo, ressocializar o agressor.

De todos os outros limites citados, surgem, também, os sociais e culturais. Afinal, culturalmente, precisamos evoluir como sociedade; precisamos mudar de concepção,

7 Disponível em: <https://professoraalice.jusbrasil.com.br/artigos/121813993/por-que-as-mulheres-naodenunciam-seus-agressores-com-a-palavra-a-sociedade $>$. 
conceitos e mentalidade em tudo que envolve a violência doméstica: mulheres não são vítimas, mas sim acometidas; mulheres não são culpadas por serem agredidas, mas sim o agressor.

\section{Dos conceitos da ética e das relações pessoais}

Segundo Mario Sérgio Cortella (2016), em uma entrevista ao GSHOW conjunto de valores e princípios que eu uso para a minha conduta no meio da sociedade, isto é, quais são os princípios para eu agir”. Em continuação, Cortella cita: “A família é o ponto de partida da formação ética".

Apesar de estarem entrelaçadas, a ética não pode ser confundida com a moral: esta é objeto daquela. Segundo José Renato Nalini (2004), "a ética é uma ciência por ter um objeto próprio, leis próprias e método próprio, enquanto que a moral é um dos aspectos do comportamento humano".

É importante mencionar o conceito de moral, para isso, notemos:

A moral é uma espécie de conjunto de hábitos e costumes de uma sociedade. A moral, em geral, faz-se de acordo com a cultura de um local em um determinado espaço de tempo. Normalmente, alguns elementos da sociedade influenciam-na, como a religião, o modo de vida da sociedade, o acesso que essa sociedade tem à informação e o uso que as pessoas de determinado recorte social fazem da informação. A moral, normalmente, é exposta sobre preceitos e, muitas vezes, expressa como normas de proibição e permissão (PORFÍRIO, 2020). ${ }^{9}$

Moralmente, as mulheres foram, ao longo dos anos, submetidas à vontade do homem e, patriarcalmente, foram (e são) colocadas em posição social inferior ao homem. No texto sagrado (Bíblico), elas não eram contadas. Como exemplo, reparemos o disposto no capítulo 6:10 do Livro de João: "E disse Jesus: Mandai assentar os homens. E havia muita relva naquele lugar. Assentaram-se pois os homens em número de quase cinco mil” (BÍBLIA, João $6,10)$.

Do lado oposto à moral, a ética tem a tarefa de acabar com essas diferenças, além de oferecer condições às mulheres, a fim de exercer a isonomia. Observemos:

8 Entrevista disponível em: http://gshow.globo.com/Rede-Bahia/Aprovado/noticia/2016/02/filosofo-mariosergio-cortella-explica-conceitos-de-moral-eetica.html\#: :text=\%E2\%80\%9CA\%20\%C3\%A9tica\%20\%C3\%A9\%20o\%20conjunto,desses\%20princ\%C3\%A Dpios\%E2\%80\%9D\%2C\%20define\%20Cortella.

${ }_{9}^{9}$ Disponível em: < https://brasilescola.uol.com.br/filosofia/diferenca-entre-etica-moral.htm>. 
O domínio dos homens nas relações sociais com as mulheres é antigo. O que chamamos, hoje, de patriarcado é a marca desse domínio, que, durante milênios (e até hoje), colocou a mulher em posição social inferior. Se pensarmos que, até a década de 1930, as mulheres não votavam na maioria das potências republicanas e que, ainda hoje, às mulheres são negados certos direitos básicos, como a liberdade de ir e vir e de se expressar, com base em preceitos morais, podemos tomar como exemplo de norma moral o tratamento dado às mulheres. Hoje a ética tem o dever de desmascarar e derrubar esse antigo domínio que subjuga e trata com inferioridade as mulheres (PORFÍRIO, 2020).

Na Constituição Federal (1988), há dispositivos que tratam sobre os preceitos éticos. Conforme podemos observar no artigo 37: "A administração pública direta e indireta de qualquer dos Poderes da União, dos Estados, do Distrito Federal e dos Municípios obedecerá aos princípios de legalidade, impessoalidade, moralidade, publicidade e eficiência (...)".

É de se saber que a referida Constituição gerou diversas mudanças culturais, institucionais e metódicas sócio-políticas arraigadas em nosso ordenamento jurídico. Não diferente, foram os avanços éticos que exigiram amoldamentos por partes de diversos seguimentos políticos, sociais e culturais.

O objetivo (i)mediato da Constituição, certamente, foi o de assegurar a cidadania e a dignidade da pessoa humana à frente de quaisquer outras exigências formais, políticas e/ou jurídicas. Assim é o preâmbulo da Constituição Federal (1988, p. 7):

Nós, representantes do povo brasileiro, reunidos em Assembleia Nacional Constituinte para instituir um Estado Democrático, destinado a assegurar o exercício dos direitos sociais e individuais, a liberdade, a segurança, o bem estar, o desenvolvimento, a igualdade e a justiça como valores supremos de uma sociedade fraterna, pluralista e sem preconceitos, fundada na harmonia social e comprometida, na ordem interna e internacional, com a solução pacífica das controvérsias, promulgamos, sob a proteção de Deus, a seguinte Constituição da República Federativa do Brasil.

Como se depreende, a ética está intrinsecamente ligada à família, que, assim como é estrutura para todas as diversidades da vida, também é estrutura para formação humana. Desse modo, quando, além de outros fatores, a família é abalada, as consequências são das mais derivadas formas, a exemplo da formação de agressores no âmbito doméstico. Verdadeiramente, a má estrutura familiar não é a única e exclusivamente a culpada por formar esses tipos de agressores, mas, com certeza, é influência considerável.

Segundo Bruschini (1997), a família é: 
(...) um grupo social composto de indivíduos diferenciados por sexo e por idade, que se relacionam cotidianamente, gerando uma complexa e dinâmica trama de emoções; ela não é uma soma de indivíduos, mas um conjunto vivo, contraditório e cambiante de pessoas com sua própria individualidade e personalidade, (BRUSCHINI, 1997, p. 77).

Do outro giro (digo: em relação à mulher), a ética, juntamente com a moral, muita das vezes inibe o combate aos crimes envolvendo violência doméstica. Muitas deixam de registrar um Boletim de Ocorrência (B.O) para não ter seu nome ventilado na sociedade. Certamente, essa filosofia pode ser modificada através da cultura, educação (básica, principalmente) e orientações sociais.

\subsection{Do conceito de violência doméstica}

Existem vários tipos de violência, não se limitando apenas a agressão física. $\mathrm{O}$ conceito é mais amplo. Como exemplo, citemos estas matrizes: física, psicológica, moral e patrimonial. Delas, surgem-se infinitos modus operandi-modos de agir.

A propósito, vejamos o artigo $5^{\circ}$ da Lei Maria da Penha (Lei n. 11.340/2006): In Verbis: "qualquer ação ou omissão baseada no gênero que lhe cause morte, lesão, sofrimento físico, sexual ou psicológico e dano moral ou patrimonial".

A violência física tem como caraterística principal o uso da força braçal ou de armas brancas ou vermelhas, podendo causar, de um simples arranhão ou hematoma à morte. Ipis verbis:

(...) que convive maritalmente com o L.C há cerca de um ano; QUE, a convivência sempre foi conturbada, pois o L.C. a agrediu fisicamente muitas vezes durante a relação e a ameaçava de morte, caso ela procurasse a polícia. QUE a mesma nunca chegou a denunciá-lo, pois temia que ele cumprisse as ameaças; (...) que o L.C. suspeitou que a DECLARANTE estava tendo um caso com o empregador, então, a agrediu fisicamente (...) QUE, o L.C. bateu na DECLARANTE com o facão, que não sabe nem o motivo porque apanhou, e que ele a proibiu de sair de casa; (...) que no dia X, L.C continuou batendo com o facão e ainda deu lhe vários socos e pontapés pelo corpo; (...) L.C. disse que se ela saísse do portão, ele iria matá-la $(. . .)^{10}$ (ABREVIAÇÃO NOSSA).

Vislumbra-se que, em um único caso, houve dois tipos de violência: a física e a psicológica, a última através das ameaças. Afinal, violência psicológica não deixa marcas

${ }^{10}$ Depoimento prestado pela requerente M.J.L.S junto à Delegacia Civil. Autos n. 608-37.2020.811.0059. Processo em segredo de justiça. 
físicas, mas, em contrapartida, tem a capacidade de humilhar ou intimidar a parte passiva da violência. Aqui, a ferramenta é o falar. No caso acima, o agressor ameaça sua companheira de morte caso saísse de casa - restrição ao direito de liberdade de ir e vir.

Há também, como mencionado, a violência sexual. Analisemos:

(...) QUE convive com o autuado há quatro meses; (...) QUE desde o início do relacionamento foi conturbado; QUE somente discutiam com frequência; (...) QUE nesta madrugada, a declarante estava tomando banho quando o suspeito adentrou o banheiro e passou a agredi-la com socos, chutes, empurrões e puxões de cabelo (...) tendo inserido o cabo da faca utilizada para ameaçá-la em sua vagina dizendo que o cabo da faca seria o pênis dele (...) QUE em seguida a levou para o quarto e manteve relação sexual com a declarante, sem seu consentimento, com a faca ao lado para intimidá-la $(\ldots)^{11}$.

Essa violência pode ser entendida como toda e qualquer forma de coibição sexual contra o ser humano, lançando ou não mão à violência física. No âmbito doméstico, ela ocorre quando o esposo ou companheiro exige uma relação sexual sem o consentimento da mulher, valendo-se de uma simples imposição "hierárquica", de gestos e/ou de palavras e, indubitavelmente, por agressões ou ameaças.

\section{Das dificuldades éticas e/ou familiares e ausência assistencial do estado para} inibir o crescimento do crime de violência doméstica

Em uma via oposta à desigualdade entre o agressor e a mulher acometida por violência doméstica, está o conceito de igualdade. O caput do artigo $5^{\circ}$ da Constituição Federal (CF) de 1988 demonstra que todos - homens, mulheres, crianças, adultos/anciões, bem como qualquer seguimento religioso, sexual - são iguais perante a lei, sem qualquer diferença, seja lá qual for a natureza (igualdade formal). De outro lado, também existe a igualdade material, que é a isonomia: "tratar igualmente os iguais e desigualmente os desiguais na medida de suas desigualdades ${ }^{12} \%$.

Acerca do tema, em 2012, o Supremo Tribunal Federal (STF) jugou procedente a Ação Direta de Inconstitucionalidade (ADI) n. 4.424 $4^{13}$, para declarar a "natureza

${ }^{11}$ Depoimento prestado pela requerente C.S.D junto à Delegacia Civil. Autos n. 1015-43.2020.811.0059. Processo em segredo de justiça.

${ }^{12}$ BARBOSA, Rui. Oração aos Moços: edição comemorativa do centenário de nascimento do grande brasileiro. São Paulo: Reitoria da Universidade de São Paulo, 1949. v. 1.

${ }^{13}$ Disponível em: < http://www.stf.jus.br/portal/cms/verNoticiaDetalhe.asp?idConteudo=199853>. 
incondicionada da ação penal em caso de crime de lesão, pouco importando a extensão desta, praticado contra a mulher no âmbito doméstico". Portanto, independentemente da vontade da mulher, em casos de violência doméstica, a ação penal será proposta pelo Ministério Público, justamente para não coibir a mulher, acometida por violência, de proteção à saúde e segurança, garantindo, assim, a tutela da dignidade da pessoa humana. Esses tratamentos diferentes são necessários para equilibrar a desigualdade coexistente entre homens e mulheres.

Segundo essa linha de raciocínio, bem como os números apresentados, no crivo ético e pessoal ou familiar, muitas mulheres deixam de relatarem os fatos às autoridades competentes.

Essas modalidades de delitos, não raras as vezes, acontecem entre quatro paredes: às escondidas. Muitas, por questões éticas, deixam de registrar um Boletim de Ocorrência (B.O) para não se sentir exposta na sociedade. Esse pensamento, assim como é estranho na leitura, é estranho, também, na prática. Para diminuí-lo, culturalmente, as mulheres precisam de instrução educacional (desde o ensino básico) e orientações sociais, como por exemplo: grupo de debates, comunidades locais e associações.

Somando-se a isso, sabe-se da insuficiência de delegacias especializadas, modo $24 \mathrm{~h}$, em âmbito nacional. A delegacia da mulher foi criada, teoricamente, para um atendimento especializado às mulheres acometidas por algum tipo de violência, com capacitação funcional específica. Segundo a tabela apresentada pelo Senado Federal (2008), em Mato Grosso existiam apenas 7 (sete) Delegacias da Mulher, sendo que 4 (quatro) estavam localizadas na Capital.

Existiam ainda, - e apenas -, 3 (três) casas de abrigo, 1 (um) centro de referências, 5 (cinco) conselhos, 4 (quatro) varas especiais e 1 (uma) Defensoria Pública ${ }^{14}$.

Não bastasse a ausência assistencial por parte do Estado para tratar da matéria, adicionando à dificuldade, por parte das mulheres, na tomada de decisão para, e.g., registrar o B.O - o que é um avanço -, bem como suportada a insuficiência significativa de delegacias especializadas, há também a falta de capacitação de agentes públicos nas delegacias comuns nos municípios interioranos, a exemplo desta região. Inclusive, a reclamação mais corriqueira é exatamente a forma como as mulheres são abordadas nas delegacias.

\footnotetext{
${ }^{14}$ Disponível em: < https://www12.senado.leg.br/institucional/omv/entenda-a-violencia/pdfs/mapeamento-dasdelegacias-da-mulher-no-brasil $>$.
} 
As dificuldades ainda persistem, mesmo após decidirem denunciar, elas precisam provar, na maioria das vezes, a agressão. Como dito, essa modalidade de delito acontece, principalmente, no íntimo dos lares. Além disso, existem várias modalidades de agressão, que são de difícil comprovação material, a exemplo da violência psicológica ou sexual. Afinal, como uma mulher vai provar que rejeitou o ato sexual?

Superadas todas essas dificuldades, ainda resta a não punição do agressor. Os motivos são diversos, mas um deles se dá em razão das dificuldades de comprovar as agressões e/ou pela ausência de punição compatível com a violência doméstica. A divulgação de fotos ou vídeos íntimos de mulheres, sem consentimento, é tipificado nos crimes contra a honra, injúria ou difamação, os quais preveem penas entre 15 (quinze) dias a 3 (três) meses. Para o crime de ameaça (artigo 147), a pena é de detenção, de 1 (um) a 6 (seis) meses ou multa. Para o crime de lesão corporal no âmbito doméstico (artigo 129, $\S 9^{\circ}$ do CP), a pena é de detenção, de 3 (três) meses a 3 (três) anos. Devido as penas máximas serem baixas, somando-se às dificuldades enfrentadas pelo Poder Judiciário como falta de servidores, magistrados e estrutura jurídica e física inadequada, muitos dos crimes prescrevem, seja pela pena em abstrato ou pela pena em concreto, aplicada em uma eventual sentença condenatória, com trânsito em julgado, seguindo-se as regras previstas no artigo 109 do Código Penal.

Certamente, esses problemas contribuem para as dificuldades na pesquisa acadêmica ou científica envolvendo violência doméstica (frisa-se: que é repudiada pelo princípio da dignidade da pessoa humana e pelos direitos humanos).

À luz da Constituição Federal (1998), a dignidade da pessoa humana constitui um dos fundamentos do Estado Democrático de Direito. Vejamos:

Art. $1^{\circ}$ A República Federativa do Brasil, formada pela união indissolúvel dos Estados e Municípios e do Distrito Federal, constitui-se em Estado Democrático de Direito e tem como fundamentos:

(...)

III - a dignidade da pessoa humana;

Atinente ao exposto, Piovesan (2000), ensina:

é no valor da dignidade da pessoa humana que a ordem jurídica encontra seu próprio sentido, sendo seu ponto de partida e seu ponto de chegada, na tarefa de interpretação normativa. Consagra-se, assim, dignidade da pessoa humana como verdadeiro super princípio a orientar o Direito Internacional e o Interno, (PIOVESAN, 2000. p. 92). 
Portanto, a ideia é, teoricamente, a dignidade da pessoa humana, princípio fundamental em nosso ordenamento jurídico, para garantir, ao menos, condições mínimas de existência digna, protegido em situação de vulnerabilidade, em detrimento ao Poder Público e/ou sociedade, quando há conflitos de interesse. Porém, não se trata de um fundamento absoluto, mas sim relativo, pois, havendo conflitos de mesmo nível hierárquico (interesses individuais), os direitos humanos podem/devem ser relativizados em cada caso concreto.

Os Direitos Humanos, por sua vez, são direitos e liberdades fundamentais que pertencem ao ser humano, sem distinção de qualquer natureza. Observemos ${ }^{15}$ :

Direitos Humanos são uma categoria de direitos básicos assegurados a todo e qualquer ser humano, não importando a classe social, raça, nacionalidade, religião, cultura, profissão, gênero, orientação sexual ou qualquer outra variante possível que possa diferenciar os seres humanos.

Porém, como se sabe, a dignidade da pessoa humana e os Direitos Humanos são frequentemente ignorados e agredidos. Como relatado no início deste trabalho, só nesta Comarca de Porto Alegre do Norte, a cada 3 (três) dias, 1 (uma) mulher registra medidas protetivas, em razão de algum tipo de agressão.

No ano de 2020 - dados extraídos no mês de agosto -, os números somam um total de 87 (oitenta e sete) medidas protetivas distribuídas, o que corresponde a 10,87 medidas registradas por mês, número que, proporcionalmente, ultrapassa o ano de 2019. Somando-se estes últimos três anos: 2020, 2019 e 2018, são 279 (duzentos e setenta e nove) medidas protetivas distribuídas no Poder Judiciário, totalizando uma média de 8,95 registros de violência doméstica por mês.

\section{Considerações finais}

Pelo exposto, percebe-se que, empiricamente, muitas mulheres acometidas por esse tipo de violência têm dificuldades de falar sobre e relatar o que de fato aconteceu (ou que está acontecendo). Quando avançam - a exemplo de registrar B.O ao comparecer em uma delegacia -, geralmente, não relatam todo o fato, seja em razão da ética, seja por motivos pessoais, familiares (incluindo-se, aqui, a manutenção do relacionamento), seja pela dificuldade em provar as alegações ou pela inadequada punição do agressor.

Outrossim, além da necessidade de fiscalização das penas aplicadas, como por exemplo, o uso de monitoramento eletrônico para prevenir que o agressor aproxime-se da

\footnotetext{
${ }^{15}$ Conceito disponível em: <https://brasilescola.uol.com.br/sociologia/direitos-humanos.htm>.
} 
vítima, ou acolhimento das mulheres em casas de abrigo específico para este fim; entendemos que para minimizar, francamente, os casos de violência doméstica (aqui em âmbito nacional), é necessário investimento nos ensinos básico e médio, com matéria para trabalhar comportamento humano, modificação de cultura e pensamento a respeito de agressões no âmbito doméstico. Acreditamos que com essa inclusão educacional, contribuiria com a diminuição dos números de violência contra a mulher.

\section{Referências}

BARBOSA. Rui. Oração aos Moços: edição comemorativa do centenário de nascimento do grande brasileiro. São Paulo: Reitoria da Universidade de São Paulo, 1949. v. 1.

BIANCHINI. Alice: Por que as mulheres não denunciam seus agressores? Com a palavra, a sociedade. Disponível em:

$<$ https://professoraalice.jusbrasil.com.br/artigos/121813993/por-que-as-mulheres-naodenunciam-seus-agressores-com-a-palavra-a-sociedade>. Acesso em 29 out. 2020.

BÍBLIA. N. T. João. In BÍBLIA. Português. A Bíblia Sagrada: Antigo e Novo Testamentos. Tradução de João Ribeiro de Almeida. São Paulo: Sociedade Bíblica do Brasil, 1969. p. 134.

BRASIL. Congresso Nacional. Lei n. 11.340/2006. Disponível em:

<http://www.planalto.gov.br/ccivil_03/_ato2004-2006/2006/lei/111340.htm>. Acesso em 19 out. 2020 .

BRASIL. Congresso Nacional. Constituição Federal de 1988. Disponível em:

$<$ http://www.planalto.gov.br/ccivil_03/constituicao/constituicaocompilado.htm>. Acesso em 19 out. 2020.

BRASIL. Senado Federal. Acesso à justiça para mulheres em situação de violência: Estudo comparativo das Delegacias da Mulher na América Latina (Brasil, Equador, Nicarágua, Peru). Disponível em: <https://www12.senado.leg.br/institucional/omv/entendaa-violencia/pdfs/mapeamento-das-delegacias-da-mulher-no-brasil>. Acesso em 19 set. 2020.

BRASIL. Senado Federal. Agência Senado: TV Senado Live discute o aumento da violência doméstica durante a pandemia. Disponível em:

$<$ https://www12.senado.leg.br/noticias/materias/2020/09/03/tv-senado-live-discute-oaumento-da-violencia-domestica-durante-a-pandemia>. Acesso em 29 out. 2020.

BRASIL. Supremo Tribunal Federal. Supremo julga procedente ação da PGR sobre Lei Maria da Penha. Disponível em: <

http://www.stf.jus.br/portal/cms/verNoticiaDetalhe.asp?idConteudo=199853>. Acesso em 19 set. 2020.

BRUSCHINI. C. Teoria crítica da família. In: AZEVEDO M. A.; GUERRA. V. N. A. (Orgs). Infância e violência: fronteira do conhecimento. São Paulo: Cortez, 1997. P. 49-77. 
GSHOW. Globo. Filósofo Mario Sergio Cortella explica conceitos de moral e ética. Disponível em <http://gshow.globo.com/Rede-Bahia/Aprovado/noticia/2016/02/filosofomario-sergio-cortella-explica-conceitos-de-moral-e-etica. Acesso em 18 out 2020.

MATO GROSSO. Tribunal de Justiça. Juíza fala sobre avanços e desafios da Vara Especializada de Violência Doméstica. Disponível em:

<https://www.tjmt.jus.br/noticias/58623\#.XpMm08hKjIU>. Acesso em 18 set. 2020.

NALINI. José Renato. Ética Geral e Profissional. São Paulo: Editora RT, 2004.

PIOVESAN. Flávia. Direitos humanos e o direito constitucional internacional. 4ed. São Paulo: Max Limonad, 2000.

PORFÍRIO. Francisco. Diferença entre ética e moral; Brasil Escola. Disponível em: $<$ https://brasilescola.uol.com.br/filosofia/diferenca-entre-etica-moral.htm >. Acesso em 31 de outubro de 2020.

UOL. Levantamento: a cada 4 minutos uma mulher é agredida no Brasil. Disponível em: <https://www.uol.com.br/universa/noticias/redacao/2019/09/09/levantamento-a-cada-4minutos-uma-mulher-e-agredida-no-brasil.htm>. Acesso em 18 set. 2020. 